\title{
Session Title: Fostering Presentation Competence: Instituting a Comprehensive Presentation Curriculum
}

Presenter Names: Gould, Elizabeth; Gram, Kaitlin

Content Area: IEP

Session Type: Practice-Oriented

\section{Introduction}

Oral presentations are a part of the curriculum in many, if not most, academic listening/speaking

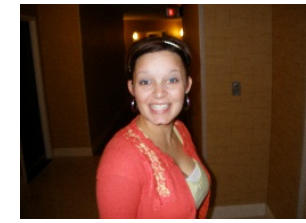

courses. Often students are required to give presentations with very little direct instruction on what constitutes a good presentation let alone how to develop and present one. In this presentation, Kaitlin Gram and I explored the importance of having an oral presentation curriculum as well as its benefits. Additionally we provided an overview of an oral presentation curriculum I began developing a few years ago, which Kaitlin further developed into a full curriculum that she has implemented in the listening/speaking courses at Missouri Southern State University.

\section{The Problem}

When I first took on the coordinating of Level 2 listening/speaking, I discovered the focus of the course, like all listening/speaking courses at the AEC, was academic listening, and consequently (and rightly) most activities had a listening focus. Despite this, students were required to give two to three formal presentations each semester, though there were no support activities in place to help them through the presentation process. As a result, the quality of these presentations was for the most part poor; they lacked discernible structure and there was a lot of plagiarism.

In order to help students improve their oral presentation competence, I assumed I would need to develop some activities to help students better understand the components of oral presentations. However, before I delved into this time-consuming task, I wanted to be sure it was worth it. Because speaking was not a focus of the AEC curriculum, I was not sure I should spend the time creating materials that might or might not be useful to students at the AEC or as they continued into their programs of study. I therefore embarked on a mini-study with the following research questions: (1) Do students actually give oral presentations in their programs of study? (2) Will they get training on giving presentations elsewhere? (3) Are there already resources out there? In other words, do I really need to create my own materials? (4) Are there benefits in addition to improved oral presentation competence that would make this project even more worthwhile? To get answers to these questions, I reviewed some literature and talked to some of the other AEC listening/speaking coordinators with the following results.

\section{Presentation requirements in university courses.}

Ferris and Tagg (1996) conducted a study on the types of listening/speaking tasks ESL students need in order to be successful in their university courses. Formal speaking ranked relatively low on what university instructors considered to be difficulties for students and many disciplines stated that formal speaking was not a part of their courses. Two disciplines however, business and engineering, stated they were "concerned with formal presentation skills” (p. 309) and wanted students to be given ample opportunity to practice formal speaking skills. In addition to this information, I drew on my own college experiences and spoke with some professors in other disciplines on the KU campus and based on these conversations combined with the information from Ferris and Tagg (1996), I concluded that students in any discipline will have to give at least one formal presentation in their academic careers and that number is more likely to be higher if they are graduate students.

\section{Will students receive formal presentation training elsewhere?}

Looking at the general education requirements for many of the undergraduate majors offered at KU, I found that most students will be required to take a speech communications course. There are two arguments against using this as a reason not to have an oral presentation curriculum in listening/speaking courses. First, according to Dale and Wolf (2006), most 
speech communication texts target native speakers and do not meet the particular needs of international students. Additionally, graduate students will most likely not have to take an introductory speech communications course and therefore would not receive this training at all.

Are there already formal presentation materials available?

There are some materials already developed and published to help students through the process of giving formal presentations. In fact, I have recently adopted one such text for Level 2 low intermediate Listening/Speaking, Present Yourself 2: Viewpoints published by Cambridge. Furthermore, many listening/speaking texts incorporate a presentation element including the Lecture Ready series published by Oxford and the Pathway series published by National Geographic/Heinle Cengage Learning. The problem is that not all programs want students to purchase two books, and due to copyright considerations, using the material from these books without purchasing them is not feasible.

\section{Are there benefits in addition to improved presentation competence?}

According to the literature, learning how to give oral presentations provides benefits outside the realm of listening/speaking. Richards (2008) states that some of the skills used for what he calls "talk as performance" are similar to those needed for formal writing including predictable organization and sequencing, and a focus on both form and accuracy, as well as using appropriate vocabulary. Based on this, it can be argued that developing presentation skills will also help students with their critical thinking and writing skills. Moreover, giving them a structure to follow, not to mention the virtue of simply surviving their presentations, will hopefully help them improve their confidence in not only formal speaking tasks but also in personal interactions though it should be mentioned that according to Richards (2008), these skills are not necessarily transferrable.

The results of my mini-study helped me conclude that creating a curriculum that would help students develop better oral presentation competence would be a worthwhile endeavor. I began the process of creating a curriculum with materials related to choosing a presentation topic, creating an outline, developing solid introductions, transitions and conclusions, and using notes effectively. These materials were used for one semester with some success. Because the materials were new, a lot of revision was needed at the end of the semester, but the presentations improved enough that I felt the work of revising the materials would be worth my time. As these materials were being piloted, however, I discovered the existence of the Present Yourself series and thought these books would work well with the Level 2 Listening/Speaking course and decided to use this book the following semester rather than revise the curriculum I had created. In the meantime, Kaitlin had gotten a job as the listening/speaking coordinator and instructor at Missouri Southern State University. Kaitlin took what I had done for one semester and developed and expanded it into a five-level oral presentation curriculum.

\section{Creating the Curriculum}

When creating the curriculum, Kaitlin had to consider the implications of it from the point of view of faculty as well as students. From the beginning of the process, Kaitlin took a top-down approach to the curriculum by first considering the overarching goal of the curriculum and how this goal would affect other instructors in the program. For example, she looked at the curriculum of the reading/writing instructors to be sure that her curriculum would validate theirs and vice versa. She wanted to be sure that any language objectives she was requiring of students would not be beyond what they were learning in other courses at the same level.

She also made sure that the curriculum was student-centered with motivation as a main focus. To do this, she made sure to include instruction and discussion on explaining why and when these skills would be needed. Additionally, she wanted to make sure to provide them with as much scaffolding as possible as well as provide them with applicable topic choices for their presentations, giving them the opportunity to expand their knowledge whether academically or culturally. Finally, she included teaching by example as a component of the curriculum, so that the instructor could model a presentation for the students. 


\section{The Curriculum}

The curriculum that Kaitlin has developed is comprehensive and includes all components teachers would need to implement it. Specifically, for each level of the curriculum, Kaitlin developed the following components:

- Scope and sequence

- $\quad$ Power points introducing each topic

- Worksheets for many of the topics

- Two or more presentations assignments including rubrics

- Student self-evaluations for each assignment

- Sample presentations

\section{Conclusion}

Like all curriculum projects, this one is a constant work in progress. That said, the results have been positive and therefore have made this effort valuable. Student performance in oral presentations has noticeably improved with the implementation of a more structured curriculum. Although having this structured curriculum does not completely take away the anxiety students feel at having to stand and speak in front of their peers, it does lessen it considerably and the confidence they gain in speaking after giving a presentation is evident. 